\title{
Influence of Spray Parameters on the Metallurgical and Functional Properties of HVOF WC Based Cermets Deposited onto Low Alloy Steel
}

\author{
S. Brioua ${ }^{1}$, K. Belmokre ${ }^{1}$, V. Debout ${ }^{2}$, P. Jacquot ${ }^{3}$, E. Conforto ${ }^{4}$, S. Touzain ${ }^{4}$ and J. Creus ${ }^{4, *}$ \\ ${ }^{1}$ LCTS, Université de Skikda, Route Elhadeik, BP 26, A-21000 SKIKDA, Algérie \\ ${ }^{2}$ Ariane Group, Rue du Général Niox, F-33165 SAINT-MEDARD-EN-JALLES, France \\ ${ }^{3}$ Bodycote, Rue Ampère F-69330 PUSIGNAN, France \\ ${ }^{4}$ LaSIE UMR 7356 CNRS, La Rochelle Université, Avenue Michel Crépeau, F-17042 LA ROCHELLE France
}

\begin{abstract}
Tungsten carbide based spray coatings are widely used in industry for application requiring abrasion, sliding, fretting and erosion corrosion resistance. High velocity oxy-fuel (HVOF) flame spraying was used for producing high quality carbide composite coatings. In this study, a WC-CoCr and WC-CoCrNi powders were thermal sprayed using a HVOF process. The spray parameters were varied in order to investigate their influence on microstructure and mechanical properties of coatings. It is possible to produce homogeneous coating by controlling the flame temperature, the velocity of the gun transverse, the powder feed rate and the nature of the powders. The mechanical properties and the porosity rate could be optimized in order to improve the functional properties.
\end{abstract}

Keywords: Cermets, HVOF, Thermal spraying, Microstructure, Porosity, Mechanical properties.

\section{INTRODUCTION}

Tungsten carbide based coatings are widely used when abrasion, sliding, fretting and erosion resistance are required. The hard WC particles provide hardness and wear resistance while the metal binder $(\mathrm{Co}, \mathrm{Ni}$, $\mathrm{CoCr}, \mathrm{NiCr}, \mathrm{CrNiCo...)}$ gives the necessary coating toughness $[1,2]$. These cermet coatings were presented as a promising alternative compared to electrolytic hard chromium coatings that conventionally use $\mathrm{Cr}(\mathrm{VI})$ based bath. But the use of these $\mathrm{Cr}(\mathrm{VI})$ salts was strongly restricted due to health and environmental toxicity. Many thermal spraying techniques such as atmospheric plasma spraying (APS) [3, 4], high velocity oxy fuel spraying (HVOF) [4-6] and detonation spray coatings (DSC) [7] are the most commonly used to deposit tungsten carbides based coatings. The main advantage of HVOF compared to other thermal spray techniques is the ability to accelerate the melted powder particles of the feedstock material at a relatively large velocity that permits to confer a fairly dense microstructure $[8,9]$. Porosity level of the WC-Co composite coatings, reported in literature, evolve from $0.4 \%$ to $5 \%$ depending on the structure, the characteristic of the initial powder and also on the operating conditions and parameters. Hardness values of WC-Co based coatings are improved for denser coatings with low porosity rate $[4,10,11]$. Furthermore,

*Address correspondence to this author at the LaSIE UMR 7356 CNRS, La Rochelle Université, Avenue Michel Crépeau, F-17042 LA ROCHELLE France; Tel: +33546457294; E-mail: jcreus@univ-Ir.fr low temperature regimes in HVOF compared to plasma spraying technique ensure less decomposition of WC particles. Decarburization and decomposition favor the formation of undesirable phases such as brittle $\mathrm{W}_{2} \mathrm{C}$ and $\mathrm{W}$ that affect the mechanical properties and corrosion resistance $[2,8,9,12,13]$. The coatings have even a small amount of pores connecting to the substrate [14]. While a large variety of metallic matrix materials are available to incorporate with the WC grains, it has been reported that the best performance in terms of wear resistance is reached when cobalt, chromium and nickel are used for the binder $[15,16]$

In the present study the spray parameters were varied to study their influence on microstructure and mechanical properties of coatings. Functional properties of these composite coatings are strongly dependent on the microstructure and the porosity rate.

\section{EXPERIMENTAL}

\subsection{Materials}

AISI 4135 low alloy steel was used as substrate. Prior to the spray process, circular $(\varnothing 2.5 \mathrm{~cm})$ samples were degreased with acetone and grid blasted with $\mathrm{Al}_{2} \mathrm{O}_{3}$ powders. WC-CoCr cermets were deposited by High Velocity Oxy-Fuel (HVOF) thermal spray technique at different deposition parameters using two compositions of powders $A$ and $B$. The nominal compositions reported by suppliers are reported in Table 1 and we can remark that powder B contains a 
Table 1: Nominal Composition of Both Powders A and B (in wt\%)

\begin{tabular}{|c|c|c|c|c|c|c|c|}
\hline & Type & W & C & Co & Ni & Cr & Fe \\
\hline \hline Powder A & WC-CoCr & 81.08 & 5.35 & 9.68 & - & 3.8 & 0.09 \\
\hline Powder B & WC-CoCrNi & $77.7-80.1$ & $5.1-5.8$ & $8.5-9.5$ & $0.8-1.2$ & $4.5-5.5$ & 0.3 max \\
\hline
\end{tabular}

larger content in chromium and the presence of nickel. It was reported that $\mathrm{Ni}$ can reduce the sintering difficulty of WC-based cemented carbide materials and enables to lower the metal binder content.

The coatings were deposited by HVOF thermal spray technique at Bodycote in a closed chamber with control temperature and projection kinematic. The speed reached by the particles is higher than $700 \mathrm{~m} / \mathrm{s}$ with the flame temperature around $2600^{\circ} \mathrm{C}$. Particles passing through the flame are then projected on the rotating substrate surface, the projection gun being animated by a translatory movement. Table $\mathbf{2}$ summarizes the deposition parameters used during this study.

Coatings were synthesized in an industrial device according to the range of parameters classically used for these cermet coatings. Values of the deposition parameters could not be communicated because coatings are dependent on industrial parameters. "Standard" deposition corresponds to the conventional optimized parameters used for the industrial deposition of WC-CoCr coatings. These parameters correspond to a good compromise between metallurgical homogeneity and mechanical resistance. The other configurations correspond to modification of one parameter compared to the standard condition, for example a reduction of the translatory movement, lowering of the flame temperature by modifying the ratio of combustive/fuel and the reduction of the powder flow.
The coatings are made from powders containing small particles of tungsten carbide embedded in a metallic phase, the binder, consisting of a mixture of $\mathrm{Co}, \mathrm{Cr}$ or $\mathrm{Ni}$. The thickness range of as-sprayed coatings was $240-300 \mu \mathrm{m}$. The roughness is $R_{a}$ of $4-5$ $\mu \mathrm{m}$.

\subsection{Characterization Procedure}

The crystalline structure of the coatings is investigated by X-ray diffraction using a Bruker Advanced D8 operating with $\mathrm{Cu} \mathrm{K}_{\alpha}(\lambda=0.154056 \mathrm{~nm})$ radiation. The analyzed range of the diffraction angle $2 \theta^{\circ}$ was between 25 and $90^{\circ}$.

Samples were observed by optical microscopy using a LEICA DM6000M equipped with polarized light and dark field observations and by scanning electron microscopy (SEM), using a FEI- Philips Quanta 200 ESEM- FEG apparatus, equipped with an energy dispersive X-ray spectrometer (EDS), which provided elemental chemical composition information for powders and coatings. Analyses were performed in high vacuum mode and at electron beam accelerating voltage of $20 \mathrm{kV}$.

\subsection{Evaluation of the Porosity}

3 different methods will be used for the evaluation of the porosity rate of the different coated steel.

The first method is based on the optical observation of coating steel cross-sections coupled with image treatment. The treatment was realized by Bodycote

Table 2: Deposition Parameters for as Sprayed WC-CoCr Based Coatings

\begin{tabular}{|c|c|c|c|c|}
\hline Ref. & Powder & Flame Temperature & Powder Feed Rate & Gun Transverse Velocity \\
\hline \hline coating 1 & A & Standard & Standard & Standard \\
\hline coating 2 & A & Standard & Standard & Reduced \\
\hline coating 3 & A & Reduced & Standard & Standard \\
\hline coating 4 & A & Standard & Standard & Standard \\
\hline coating 5 & B & Standard & \\
\hline
\end{tabular}


using Image $\mathrm{J}$ for the treatment of the optical images. The electrochemical method is based on the determination of the electrochemical parameters in a saline solution after one hour of immersion. Artificial seawater was used for this experiment and the preparation is described in [17].

Polarisation curves were obtained through a potentiodynamic experiment that consist on a potential sweep from $\pm 0,15 \mathrm{~V}$ around the open circuit potential at a scan rate of $0,2 \mathrm{mV} / \mathrm{s}$. A conventional 3-electrodes device was used composed of a saturated calomel electrode as the reference electrode and a large platinum grid for the counter electrode. The electrodes are connected to a Metrohm Autolab PGP 302 potentiostat driven by GPES.

The last method for the porosity rate is a chemical method based on the ISO 10309:1994 standard [18].

\section{RESULTS AND DISCUSSION}

\subsection{Characterization of the Morphology and Structure of the Powder A and B}

Figure 1 presents, respectively the SEM images of the starting $\mathrm{WC}-\mathrm{CoCr}$ powders A and B. Both powders are composed of spherical and agglomerated particles with an average size of 27-29 $\mu \mathrm{m}$. Powder compositions are different, nickel was incorporated in powder B. The powder B is highly porous, with large holes within the spherical particles.
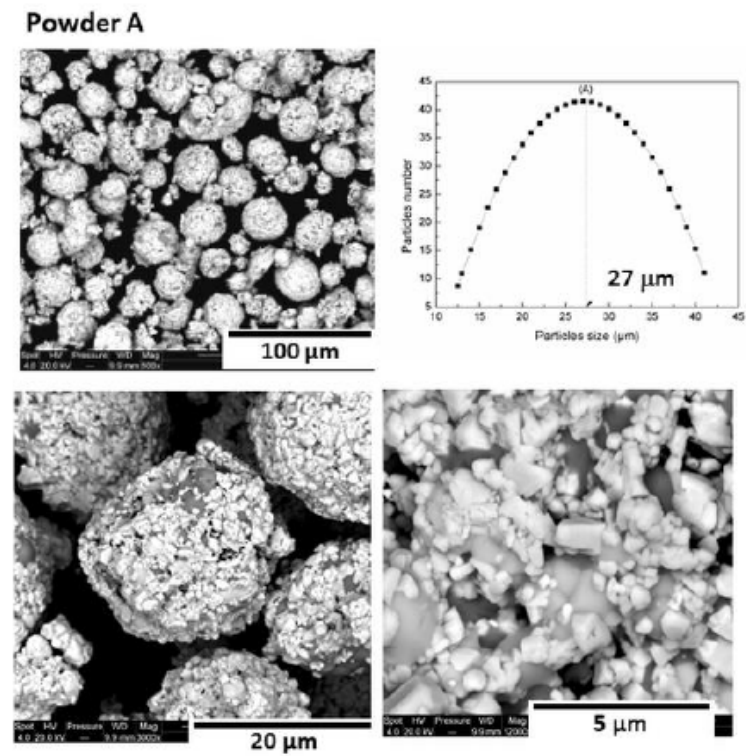

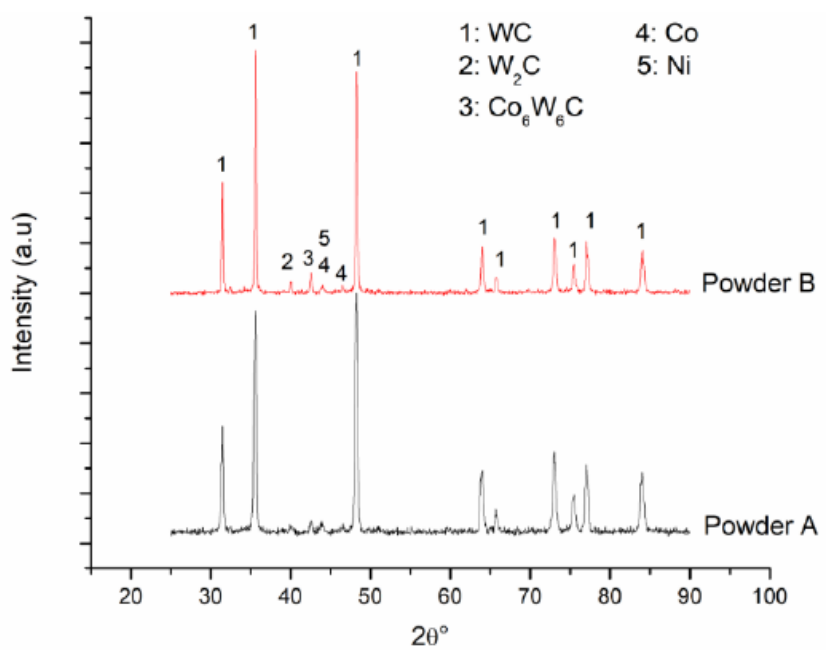

Figure 2: XRD patterns of powders $\mathbf{A}$ and $\mathbf{B}$.

X-ray spectra of the starting powders $A$ and $B$ are presented in Figure 2. The diffraction patterns present different peaks that could be related to WC, but other small peaks corresponding to $\mathrm{W}_{2} \mathrm{C}$, mixed carbide $\left(\mathrm{Co}_{6} \mathrm{~W}_{6} \mathrm{C}\right)$ and cubic cobalt and $\mathrm{Ni}$ are also observed.

\subsection{Morphology and Microstructure of HVOF as- sprayed Coatings}

\subsubsection{Surface Morphology of the WC Composite Coatings}

The SEM images (Figure 3) show the characteristic morphology of the as-sprayed coatings. This morphology was produced during the powder manufacturing process at different parameter deposition.
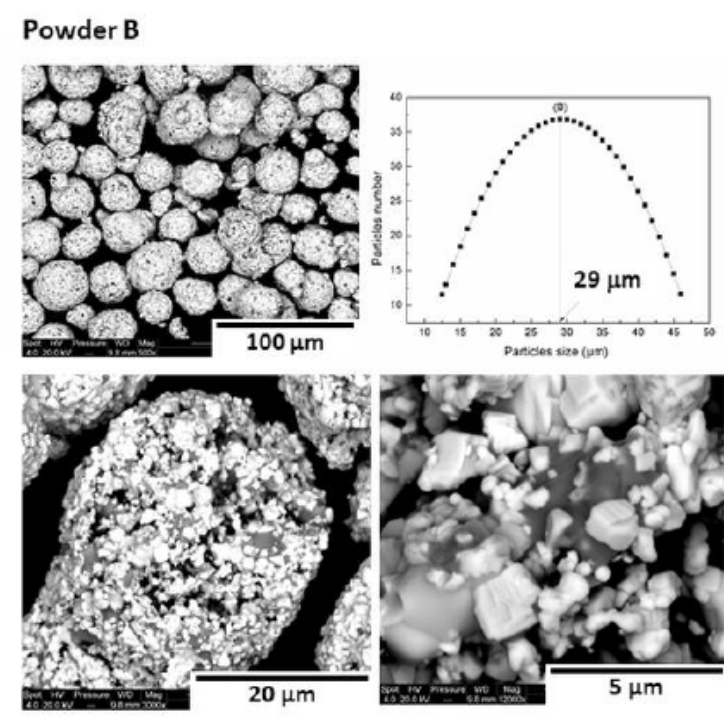

Figure 1: SEM images and statistical approaches: (A) powder A; (B) powder B. 


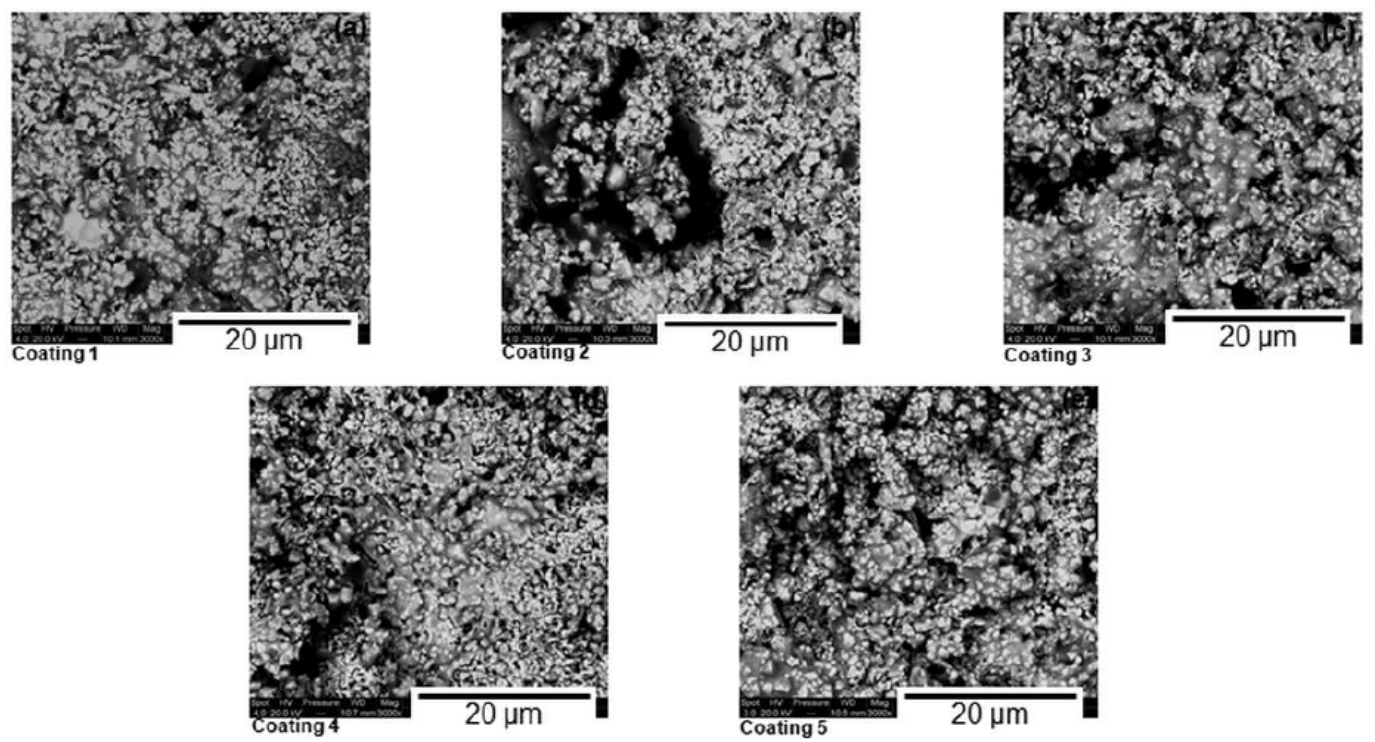

Figure 3: SEM images of as-sprayed WC-CoCr based coatings.

We see two phases with different contrasts: the WC particles in light contrast and the cobalt metallic phase (matrix) in dark contrast.

The tungsten carbide particles are well distributed and embedded into the cobalt matrix. The standard parameters (coating 1 ) giving as a result a more homogeneous coating structure. The SEM images of the coating 2 (Figure $3 \mathbf{b}$ ) and coating 3 (Figure 3c) samples are elaborated respectively with decreasing Gun transverse velocity and flame temperature showing a heterogeneous distribution of metallic binder. The decrease in gun velocity induces a greater amount of deposited material inducing less rapid cooling at the substrate. The temperatures at the substrate level are then higher allowing a redistribution of the binder around the tungsten carbide particles. If the flame temperature is lowered, the melting of the powder particles may be incomplete and moreover, the wettability of the binder with the particles may also be affected. Agglomerates of particles are then observed, reflecting a poor distribution of the binder around the WC particles. Incorporation of nickel was reported as a beneficial element that increases the wettability with the carbide particles [16]. The coating 4 (Figure 3d) sample was obtained using a lower flux of powder than that measured for all coatings. We observe a more homogeneous distribution of the metal binder compared to the reference condition. Indeed, the decrease in the powder flow improves the melting of the binder then increasing the wettability around the tungsten carbide particles. The structure of coating 5 obtained with the powder B (Figure 3e) shows a great amount of defects compared to coating 1 .

\subsubsection{Microstructure of the WC Composite Coatings}

The XRD spectra for the as-sprayed coatings are presented in Figure 4. The identified phases are WC, $\mathrm{W}_{2} \mathrm{C}, \mathrm{Co}_{6} \mathrm{~W}_{6} \mathrm{C}$ as initially detected on powders $\mathrm{A}$ and $\mathrm{B}$ [5]. According to the XRD patterns of both powders and coatings, transformations occur during spraying. The peak diffraction of the WC phase is still present but it seems that the amount of $\mathrm{W}_{2} \mathrm{C}$ has increased for coatings 2,3 and 5 as compared to the powders.

No diffraction peaks characterizing the metal matrix are detected, contrary to the analyses performed on powders $A$ and $B$. The rapid cooling of the sprayed liquid droplets would lead to an amorphous metallic matrix. According to the literature [19], the presence of carbon from the decomposition of WC particles could promote the amorphization of the metal matrix. It should be noted that the amorphous metal phase could have a better resistance to corrosion in saline environment, especially because of the absence of crystalline defects (grain boundaries, dislocation etc ...) [20-22].

Table 3 provides a quantitative analysis of the species present in the coatings from the analyses of the diffraction spectra. The presences of $\mathrm{W}_{2} \mathrm{C}$ and mixed carbide $(\mathrm{Co}, \mathrm{W}) \mathrm{C}$ are characteristic from a decarburization phenomenon observed in the case of cermet deposits. 


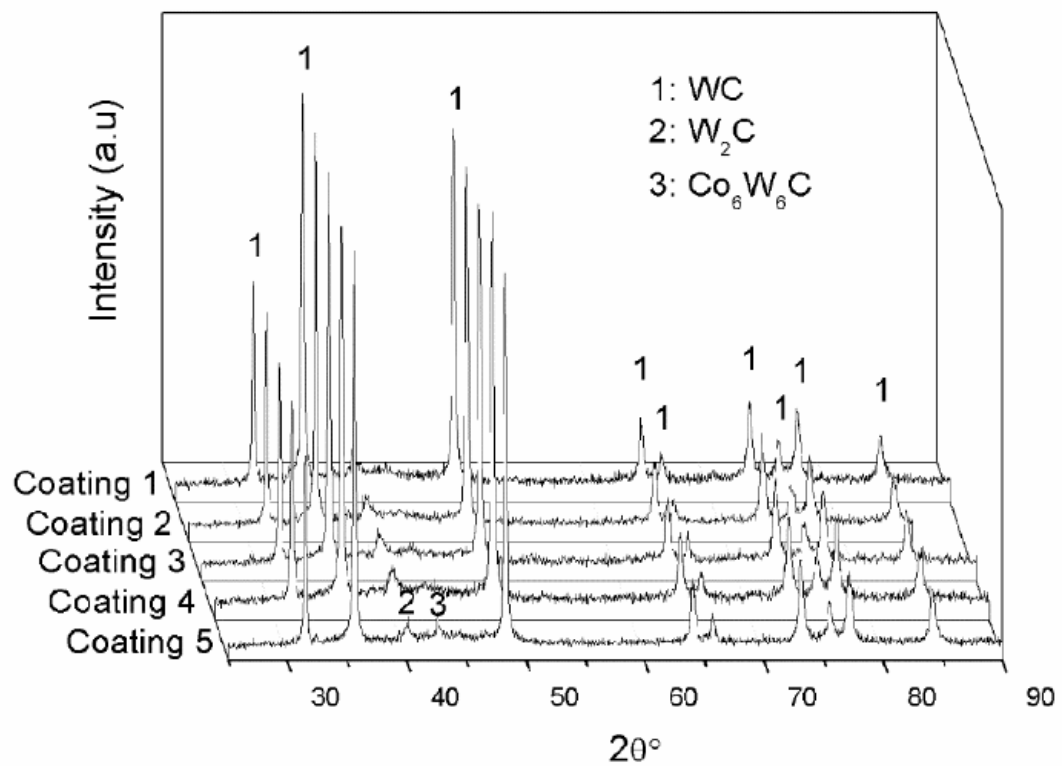

Figure 4: XRD patterns of as-sprayed WC-CoCr based coatings.

Table 3: XRD Analysis of the Content of Crystalline Phases in the Powder and the WC-CoCr Based Coatings

\begin{tabular}{|c|c|c|c|c|c|c|c|}
\hline Phases (\% wt) & Starting powder A & Coating 1 & Coating 2 & Coating 3 & Coating 4 & Starting powder B & Coating 5 \\
\hline \hline $\mathrm{WC}$ & 96.34 & 95.76 & 94.40 & 93.62 & 95.60 & 94.54 & 94 \\
\hline $\mathrm{W}_{2} \mathrm{C}$ & 0.77 & 3.02 & 4.25 & 4.44 & 3.06 & 0.88 & 3 \\
\hline $\mathrm{Co}_{6} \mathrm{~W}_{6} \mathrm{C}$ & 1.07 & 1.22 & 1.35 & 1.94 & 1.34 & -2.05 & 1.65 \\
\hline $\mathrm{Co}$ & 1.82 & - & - & - & - & - & - \\
\hline $\mathrm{Cr}$ & - & - & - & - & - & - & - \\
\hline $\mathrm{Ni}$ & - & - & - & - & - & -88 \\
\hline
\end{tabular}

The secondary phase $\left(\mathrm{W}_{2} \mathrm{C}\right)$ appears due to the decarburization process taking place at high temperatures in the flame [2]. The degradation consists of a carbon lost from the WC phase and dissolution of carbon and tungsten in the metallic binder phase that leads to the formation of brittle $\mathrm{W}_{2} \mathrm{C}$ and mixed (Co,W)C phase. Mechanisms that were suggested for the decarburization degradation is composed of thermal decomposition and oxidation mechanism [2, 23, 24]:

\section{Thermal decomposition}

$$
2 \mathrm{WC} \longrightarrow \mathrm{W}_{2} \mathrm{C}+\mathrm{C}
$$

\section{Oxidation mechanism}

$$
\begin{aligned}
& \mathrm{W}_{2} \mathrm{C}+\mathrm{O}_{2} \longrightarrow \mathrm{W}+\mathrm{CO}_{2} \\
& 2 \mathrm{~W}_{2} \mathrm{C}+\mathrm{O}_{2} \longrightarrow 2 \mathrm{~W}_{2}(\mathrm{C}, \mathrm{O}) \\
& \mathrm{W}_{2}(\mathrm{C}, \mathrm{O}) \longrightarrow 2 \mathrm{~W}+\mathrm{CO}
\end{aligned}
$$

In HVOF, it is difficult to separate the role of thermal decomposition in total decarburization from that of oxidizing decarburization. As far as thermal decomposition is mainly concerned, decreasing the heat of a flame will effectively decrease the decomposition of tungsten carbide [23]. According to the coating 3 that was performed using a lower flame temperature, the value of the carbide phase content (around 6,94 wt.\%) is very important suggesting that in our deposition conditions, the decarburization of the WC particles is due to both thermal and oxidation mechanisms. This decarburization was also observed by Farokhzadeh \& al [25] during the characterization of WC-Co based composites and the deposition parameters permit to limit their content. These two compounds are initially present in the composition of powders $A$ and $B$, probably related to the technique of synthesis of these agglomerated powders. The development of coatings by thermal spraying HVOF 
leads to a variation in the composition of species detectable in XRD. The evolutions obtained are dependent on the operating conditions of deposition and also the powder characteristic (particle size and powder fleed rate) $[16,19,25,26]$. Thus, decarburization is low for coatings 1 and 4 . The decrease in the powder feed rate allows a better distribution of the liquid binder around the tungsten carbide particles, thus limiting the phenomenon of surface oxidation. On the other hand, the decrease in particle velocity and temperature led to an increase in the content of $\mathrm{W}_{2} \mathrm{C}$ in the deposit, indicating significant decarburization related to these changes in deposition parameters [16].

The respective decrease in the gun transverse velocity and the temperature of the flame leads to the increase of the contact times, at high temperatures, of WC particles to oxygen from the atmosphere. This promotes the surface degradation of tungsten carbide particles. The incorporation of nickel in the composition of the metallic binder in the coating 5 does not seem to limit the decarburisation mechanism since the amount of the carbide phases $\left(\mathrm{W}_{2} \mathrm{C}\right.$ and mixed $\left.(\mathrm{Co}, \mathrm{W}) \mathrm{C}\right)$ is quite similar to coatings 1 and 4 . We can suppose that a minimal amount of nickel is require to favour the wettability of the liquid phase around the WC particles during the projection step towards the substrate.

\subsection{The Porosity of as-sprayed Coatings}

Composite coatings synthesized by thermal spray deposition technique have good anti-wear properties.
Nevertheless, the use of lubricants to promote contact and limit wear could induce physico-chemical interactions leading to degradation of the coating or substrate. The fluid must then infiltrate through the coating following preferential paths that would allow access of the corrosive medium to the substrate. Thus, the determination of the open porosity rate is a key factor in the durability of coated steel [27].

For the evaluation of the porosity rate, three different techniques were used: chemical, electrochemical and physical. These techniques have been widely described in the case of the characterization of ceramic coatings based on nitride deposited by PVD on steel substrate [27]

\subsubsection{Physical Techniques using Optical Observations}

Optical observations of cross-sections of the different coatings (Figure 5) were performed by Bodycote. Image analyses make possible to evaluate the porosity rate of the different configurations. These analyses give indications on the average porosity of the coatings. The average porosity obtained by optical microscopy is at around $0.08 \%$ per volume, it is practically constant for all the configurations.

The porosity rate deduce from optical analyses are gathered in Table 4. The values of porosity are quite similar for all the samples.
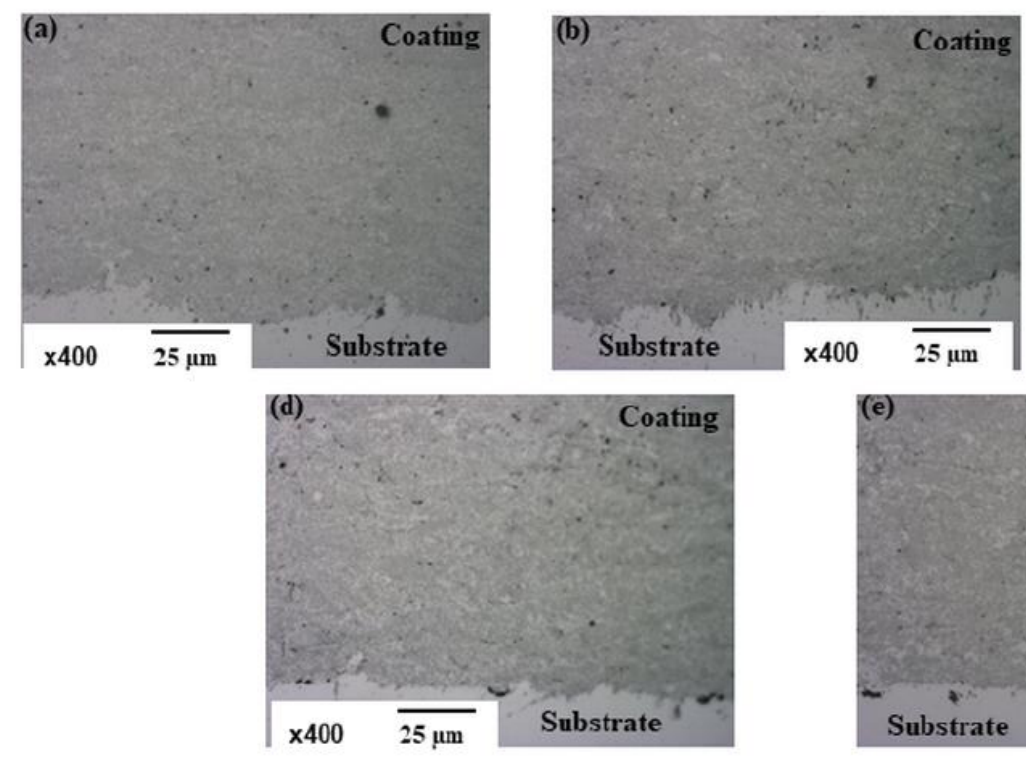
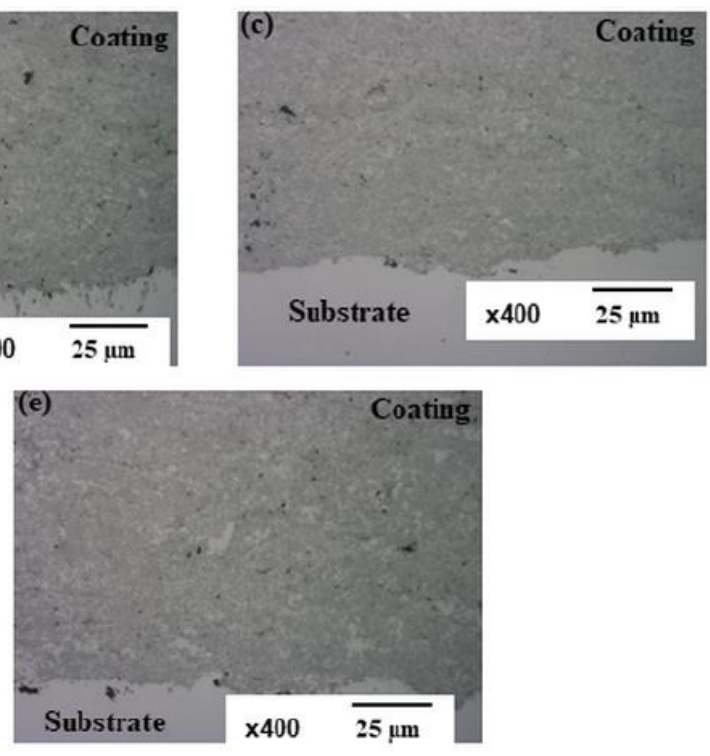

Figure 5: Optical micrographs of cross sections of HVOF WC-CoCr based coatings. 
Table 4: Porosity Rate of WC-CoCr Based Coatings Deduced from Image $\mathrm{J}$ Treatment

\begin{tabular}{|c|c|c|}
\hline & Thickness $(\boldsymbol{\mu m})$ & $\begin{array}{c}\text { Porosity (\%) } \\
\text { Optical observation }\end{array}$ \\
\hline \hline Coating 1 & 230 & 0.08 \\
\hline Coating 2 & 231 & 0.09 \\
\hline Coating 3 & 227 & 0.07 \\
\hline Coating 4 & 220 & 0.18 \\
\hline Coating 5 & 203 & 0.08 \\
\hline
\end{tabular}

\subsubsection{Electrochemical Techniques}

For the estimation of the porosity rate we used two methods. The first method is to assume that there is no galvanic coupling between the substrate and the coating. This one is considered electrochemically inert. In this case, the porosity rate is reflecting the ratio of steel surface in contact with the electrolyte:

$$
\mathrm{P}=\left(\frac{R p_{\text {sub }}}{R p_{\text {coat }}}\right) \times 10^{-\left|\frac{\Delta E_{\text {corr }}}{b_{a}}\right|_{X 100}}
$$

where $P$ is the open porosity rate $(\%), R p_{\text {sub }}$ and $R p_{\text {coat }}$ are respectively the polarisation resistance of the substrate and the coated steel, $\Delta$ Ecorr $=$ Ecorr (substrate)- Ecorr (coating) and ba is the Tafel anodic slope of the steel polarization curve.
The second method is based on the fact that a galvanic coupling between the substrate and the coating could exist. It is so necessary to take into account the amplification of the dissolution mechanism that could be produced by the galvanic corrosion [27]. The fraction of the active substrate surface is deduced from the polarization curve obtained after an initial immersion time of 1 hour in the aggressive solution.

$$
S_{A}=\left(\frac{i_{\text {corr }} \text { rev }}{i_{g}}\right) \times 100
$$

where $S_{A}$ is the active surface ratio of steel (\%), icorr rev : corrosion current density of the coating and ig : galvanic current density.

Figure 6 presents the polarization curves of the different coatings compared with bare substrate after an immersion of 1 hour in the saline solution. The electrochemical parameters deduced from these curves like corrosion potential and corrosion current densities are gathered in Table $\mathbf{5}$.

We can first observe that the different coatings induce a large shift of the corrosion potential toward positive values, suggesting that the WC based composite coatings are nobler than steel substrate. Porosity rates obtained from both methods are also presented in Table $\mathbf{5}$.

We notice a slight difference between the porosity rates estimated from both methods. The porosity rates are in the same range of values, we only observed a large difference for coatings 3 and 4 . The porosity rate

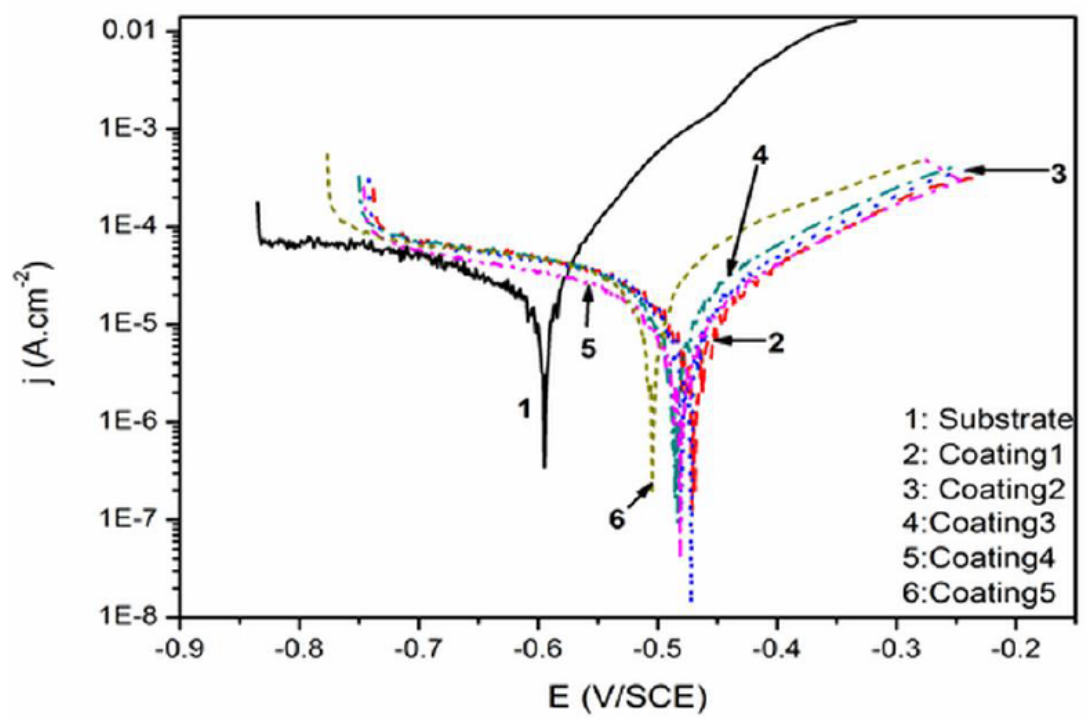

Figure 6: Polarization curves of steel and WC-CoCr based coatings after one hour of immersion in seawater. 
Table 5: Electrochemical Characteristics Deduced from Polarisation Curves of Coated Samples

\begin{tabular}{|c|c|c|c|c|}
\hline Ref. & $\mathrm{E}_{\text {corr }}(\mathrm{mV} / \mathrm{SCE})$ & $\mathrm{J}_{\text {corr }}\left(\mu \mathrm{A} / \mathbf{c m}^{2}\right)$ & Porosity rate $\mathbf{P}(\%)$ & Porosity rate $\mathbf{S}_{\mathbf{A}}(\%)$ \\
\hline \hline Coating 1 & -462 & 11 & 2,94 & 2.3 \\
\hline Coating 2 & -480 & 15.5 & 3.94 & 3.3 \\
\hline Coating 3 & -482 & 17.4 & 0.7 & 5.0 \\
\hline Coating 4 & -484 & 10 & 0,5 & 2.6 \\
\hline Coating 5 & -506 & 24.8 & 9,53 & 10.6 \\
\hline
\end{tabular}

determined by electrochemical methods are ranging between 2.3 and $5 \%$, which is similar for the porosity rates described in the literature for HVOF WC based coatings [25]. A porosity rate of $5 \%$ is obtained when the temperature of the flame is reduced whereas the reduction of the powder feed rate leads to a decrease of the porosity. Coating 5 presents the highest porosity rate for both electrochemical methods, the obtained value is around $10 \%$. This is directly related to the more heterogeneous microstructure identified for this deposition configuration.

\subsubsection{Chemical Techniques using the Ferroxyl Test}

This technique consists in provoking a local attack of the substrate by an aggressive solution whose composition is suitably defined so as not to degrade the coating. This aggressive solution infiltrates through the open defects of the coating. This solution causes a dissolution of the steel that release iron(II) metallic ions. The released ions rise along the preferential paths of infiltration and the presence of complexing agents makes it possible to localize the place of emergence of these compounds by a particular color change.

This technique is only use in the case of a coating that is nobler than the substrate, this makes it possible to use a solution that selectively attacks the substrate without interacting with the coating. In the case of steel substrate, the corrosive solution is composed of a mixture of potassium ferro-ferri cyanide of composition reported in Table 6.

Table 6: Composition of the Corrosive Solution for Ferroxyl Test [18]

\begin{tabular}{|c|c|}
\hline & Concentration (g/L) \\
\hline \hline $\mathrm{K}_{3} \mathrm{Fe}(\mathrm{CN})_{6}$ & 10 \\
\hline $\mathrm{K}_{4} \mathrm{Fe}(\mathrm{CN})_{6}, 3 \mathrm{H}_{2} \mathrm{O}$ & 10 \\
\hline $\mathrm{NaCl}$ & 60 \\
\hline
\end{tabular}

A specific paper is soaked in the corrosive solution and located few minutes on the surface of the coated steel surface. A limitation of this technique lies in the thickness of the deposits. For this characterization, the thickness of the deposits is limited to $80 \mu \mathrm{m}$ in order to promote the infiltration of the aggressive After ten minutes, the formation of blue dots associated to a complex based on ferro-cyanide on the surface corresponding to the products of iron(II) corrosion is observed. Using an optical microscope we were able to estimate the total surface attacked and the porosity rate " $F$ " is determined from these optical observations as follows:

$$
F(\%)=\frac{S_{A}}{S_{T}} \cdot 100
$$

where $S_{A}$ is the attacked surface of the coated sample and $S_{T}$ is the total surface of the coated steel exposed to the aggressive solution. Table 7 gives the result of the porosity rate deduced from the ferroxyl test.

Table 7: Porosity Rate Deduced from the Chemical Ferroxyl Test

\begin{tabular}{|c|c|}
\hline & Porosity Rate F (\%) \\
\hline \hline Coating 1 & 2.15 \\
\hline Coating 2 & 3.35 \\
\hline Coating 3 & 3.4 \\
\hline Coating 4 & 4.5 \\
\hline Coating 5 & 10 \\
\hline
\end{tabular}

The observation of blue dots gives information on the active surface of the steel in contact with the aggressive solution. The porosity values are in quite agreement with the values reported in the literature for HVOF WC composite coatings and the coating 5 obtained from a modified binder composition present the highest value of porosity [25]. 
Figure 7 shows the porosity rates of the different grades estimated by the different methods mentioned above. We note that the coatings with a more or less homogeneous distribution on the surface have the lowest porosity rates (case of coatings 1 and 4 ).

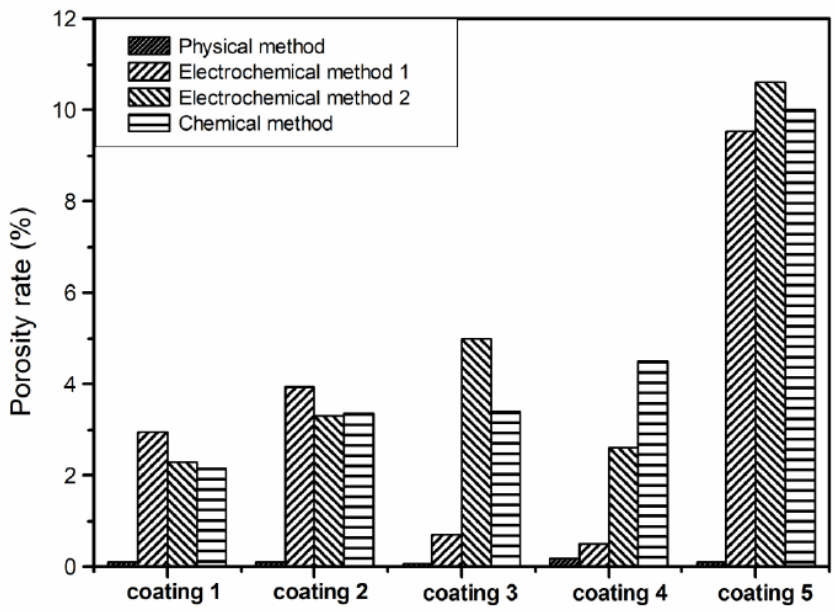

Figure 7: Porosity rate of as-sprayed HVOF coatings deduced from physical, chemical and electrochemical methods.

The porosity rates estimated by the physical method are very low compared to those estimated by the chemical and electrochemical method. This difference arises from the fact that the physical analyses are carried out on cross-sections then analyzing a very small surface of the sample (thickness of the deposit), whereas chemical and electrochemical methods evaluate the entire surface of the coated part in contact with the attack solution. In addition, it should be noted that physical analyses require surface preparation after cutting the samples. This range of sample preparation could cause pore clogging if the metal matrix is ductile, which is the case with the $\mathrm{CoCr}(\mathrm{Ni})$ matrix. We can underline that the chemical and electrochemical methods give porosity rate that are in the same range of values. In the case of cathodic coating, it seems that these techniques give relevant values that are in good agreement with values reported for similar HVOF coatings [25].

\subsection{The Microhardness of As-sprayed Coatings}

Figure 8 shows the influence of variation of deposition parameters on microhardness of HVOF coatings. The micro hardness for all coatings was found to lie in the range of $1035-1219 \mathrm{HV}_{0.3}$. This is higher than the values found in a previous study for WC-based coatings [28]. The values of microhardness for coating 1 and 4 are higher than the others this is due to the homogeneous coating structure and the lowest amount of $\mathrm{W}_{2} \mathrm{C}$ phase.

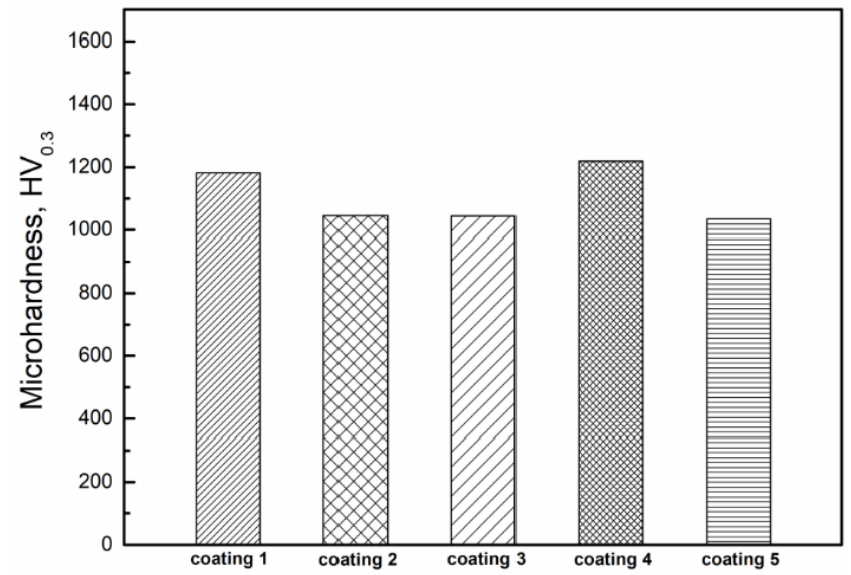

Figure 8: Microhardness of HVOF as-sprayed coatings.

\section{CONCLUSION}

The microstructure of as-sprayed cermet coatings deposited onto steel has been studied. The results show that WC-CoCr coatings that possess excellent surface properties, such as lower porosity and higher microhardness, were prepared by high pressure high velocity oxygen fuel spraying (HP-HVOF) at different parameters deposition. $\mathrm{WC}$ and $\mathrm{W}_{2} \mathrm{C}$ are still present, and $\mathrm{Co}_{6} \mathrm{~W}_{6} \mathrm{C}$ has appeared in addition to the initial powder. The relative content of $\mathrm{W}_{2} \mathrm{C}$ has increased during HP-HVOF process. The coatings prepared under standard parameters and low powder feed rate present a homogeneous and densified microstructure. The optimisation of the deposition parameters permits to enhance the functional properties like durability and mechanical resistance.

\section{REFERENCES}

[1] Zhang SD, Cho TY, Yoan JH, Fang W, Song KO, Li MX, Loo YK, Lee CG. Characterization of microstructure and surface properties of hybrid coatings of $\mathrm{WC}-\mathrm{CoCr}$ prepared by laser heat treatment and high velocity oxygen fuel spraying. Mater. Charact. 2001; 59: 1412-6.

https://doi.org/10.1016/j.matchar.2008.01.003

[2] Magnani M, Suegama PH, Espallargos N, Dosta S, Fugivara CS, Guilemany JM, Beneditti AV. Influence of HVOF parameters on the corrosion and wear resistance of WC-Co coatings sprayed on AA7050 T7. Surf. Coat. Technol. 2008; 202: 4746-11

https://doi.org/10.1016/j.surfcoat.2008.04.055

[3] Subrahmanyam J, Srivastava MP, Sivakumar R. Characterization of plasma-sprayed WC-Co coatings. Mater. Sci. Eng. 1986; 84: 209-5. https://doi.org/10.1016/0025-5416(86)90240-5

[4] Li, CJ. Ohmori A, Harada AY. Effect of powder structure on the structure of thermally sprayed WC-Co coatings. J. Mater. Sci. 1996; 31: 785-9.

https://doi.org/10.1007/BF00367900 
[5] Verdon C, Karimi A, Martin JL. A study of high velocity oxyfuel thermally sprayed tungsten carbide based coatings. Part 1: Microstructures. Mater. Sci. Eng. 1998; A246: 11-13. https://doi.org/10.1016/S0921-5093(97)00759-4

[6] Schwetzke R, Kreye $H$. Microstructure and properties of tungsten carbide coatings sprayed with various high-velocity oxygen fuel spray systems. J. Therm. Spray Technol. 1999; 8: 433-6. https://doi.org/10.1361/105996399770350395

[7] Suresh P, Babu P, Basu B, Sundararajan G. Processingstructure-property correlation and decarburization phenomenon in detonation sprayed WC-12Co coatings. Acta Mater. 2008; 56: 5012-14.

https://doi.org/10.1016/j.actamat.2008.06.023

[8] Sahraoui T, Guessasma S, Ali Jeridane M, Hadji M. HVOF sprayed WC-Co coatings: Microstructure, mechanical properties and friction moment prediction. Mater. Des. 2010; 31: 1431-6.

https://doi.org/10.1016/j.matdes.2009.08.037

[9] Chivavibul P, Watanabe M, Kuroda S, Kawakita J, Komatsu M, Sato K, Kitamura J. Development of WC-Co coatings deposited by warm spray process. J. Therm. Spray Technol. 2008; 17: 750-6.

https://doi.org/10.1007/s11666-008-9271-4

[10] Chidambaram D, Clayton CR. Dorfman, MR. Evaluation of the electrochemical behavior of HVOF-sprayed alloy coatings. Surf. Coat. Technol. 2004; 176: 307-10. https://doi.org/10.1016/S0257-8972(03)00809-0

[11] Perry JM, Neville A, Wilson VA, Hodgkiess T. Assessment of the corrosion rates and mechanisms of a WC-Co-Cr HVOF coating in static and liquid-solid impingement saline environments. Surf. Coat. Technol. 2001; 137: 43-8. https://doi.org/10.1016/S0257-8972(00)01062-8

[12] Celik E, Culha O, Uyulgan B, Ak Azem NF, Ozdemir I, Turk A. Assessment of microstructural and mechanical properties of HVOF sprayed WC-based cermet coatings for a roller cylinder. Surf. Coat. Technol. 2006; 200: 4320-8. https://doi.org/10.1016/j.surfcoat.2005.02.158

[13] Bolelli G, Lusvarghi L, Giovanardi R. A comparison between the corrosion resistances of some HVOF-sprayed metal alloy coatings. Surf. Coat. Technol. 2008; 202: 4793-16. https://doi.org/10.1016/j.surfcoat.2008.04.056

[14] Yandouzi M, Jodoin B. Cermet coatings prepared by pulsed gas dynamic spraying process: Effect of the process parameters. Surf. Coat. Technol. 2008; 203: 104-10. https://doi.org/10.1016/j.surfcoat.2008.08.018

[15] Hochstrasser-Kurz S, Mueller Y, Latkoczy C, Virtanen S, Schmutz P. Analytical characterization of the corrosion mechanisms of WC-Co by electrochemical methods and inductively coupled plasma mass spectroscopy. Corros. Sci. 2007; 49: 2002-18.

https://doi.org/10.1016/j.corsci.2006.08.022

[16] Pereira P, Vilhena LM, Sacramento J, Senos AMR, Malheiros LF, Ramalho A. Abrasive wear resistance of WCbased composites, produced with $\mathrm{Co}$ or Ni-rich binders. Wear, 2021; 482-483: 203924.

https://doi.org/10.1016/j.wear.2021.203924
[17] Brioua S, Belmokre K, Debout V, Jacquot P, Conforto E, Touzain S, Creus J. Corrosion behavior in artificial seawater of thermal-sprayed WC-CoCr coatings on mild steel by electrochemical impedance spectroscopy. J. Solid State Electrochem. 16 (2012) 633-648 https://doi.org/10.1007/s10008-011-1403-y

[18] ISO 10309:1994- standard on Metallic coatings - Porosity tests - Ferroxyl test

[19] Henderson LB, Ekerdt JG. Effect of phosphorus and carbon incorporation in amorphous cobalt films prepared by chemical vapor deposition. J. Electrochem. Soc. 2010; 157: D29-5. https://doi.org/10.1149/1.3251283

[20] Perez A, Billard A, Rebere C, Berziou C, Touzain S, Creus J. Influence of metallurgical states on the corrosion behaviour of Al-Zn PVD coatings in saline solution. Corros. Sci. 2013; 74: $240-9$. https://doi.org/10.1016/j.corsci.2013.04.048

[21] Perez A, Sanchette F, Billard A, Rebere C, Berziou C Touzain S, Creus J. Comparison of the intrinsic properties of EBPVD Al-Ti and Al-Mg coatings. Mater. Chem. Phys. 2012; 132: $154-7$.

https://doi.org/10.1016/j.matchemphys.2011.11.013

[22] Lakdhar I, Alhussein A, Capelle J, Creus J. Al-Ti-W alloys deposited by magnetron sputtering: Effective barrier to prevent steel hydrogen embrittlement. Appl. Surf. Sci. 2021; 567: 150786.

https://doi.org/10.1016/j.apsusc.2021.150786

[23] Wang $\mathrm{YY}, \mathrm{Li} \mathrm{CJ}$, Ohmori A. Examination of factors influencing the bond strength of high velocity oxy-fuel sprayed coatings. Surf. Coat. Technol. 2006; 200: 2923-5. https://doi.org/10.1016/j.surfcoat.2004.11.040

[24] Yuan J, Zhan Q, Huang J, Ding S, Li H. Decarburization mechanisms of WC-Co during thermal spraying: Insights from controlled carbon loss and microstructure characterization. Mater. Chem. Phys. 2013; 142: 165-6. https://doi.org/10.1016/j.matchemphys.2013.06.052

[25] Farokhzadeh K, Fillion RM, Edrisy A. The Effect of Deposition Rate on Microstructural Evolution in WC-Co-Cr Coatings Deposited by High-Velocity Oxy-Fuel Thermal Spray Process. J. Mater. Eng. Performance 2019; 28: 741911.

\section{https://doi.org/10.1007/s11665-019-04502-4}

[26] Lyu $X$, Jiang $X$, Sun $H$, Shao $Z$. Microstructure and mechanical properties of WC-Ni multiphase ceramic materials with $\mathrm{NiCl} 2 \cdot 6 \mathrm{H} 2 \mathrm{O}$ as a binder. Nanotechnology Reviews 2020; 9: 543-14. https://doi.org/10.1515/ntrev-2020-0044

[27] Creus J, Mazille $\mathrm{H}$, Idrissi $\mathrm{H}$. Porosity evaluation of protective coatings onto steel, through electrochemical techniques. Surf. Coat. Technol. 2000; 130: 224-8. https://doi.org/10.1016/S0257-8972(99)00659-3

[28] Berger LM, Saaro S, Naumann T, Wiener M, Weihnacht V, Thiele S, Suchánek J. Microstructure and properties of HVOF-sprayed chromium alloyed WC-Co and WC-Ni coatings. Surf. Coat. Technol. 2008; 202: 4417-4. https://doi.org/10.1016/..surfcoat.2008.04.019

DOI: https://doi.org/10.31875/2410-4701.2022.09.01

(c) 2022 Brioua et al.; Zeal Press.

This is an open access article licensed under the terms of the Creative Commons Attribution License (http://creativecommons.org/licenses/by/4.0/) which permits unrestricted use, distribution and reproduction in any medium, provided the work is properly cited.. 